\title{
Study of the Motion Graphic Design at the Digital Age
}

\author{
Lu Geng \\ College of Sino-Korea Multimedia Design \\ Shanghai University of Engineering Science \\ Shanghai, China
}

\begin{abstract}
At the digital age, Motion Graphics becomes an indispensable important component in the dynamic media. As a cross- subject research direction, Motion Graphic design is the combination of graphic design and animation. From the perspective of information transmission, this paper studies the performance and unique narrative of motion graphic design.
\end{abstract}

Keywords-motion graphics; information transmission; animation; design

\section{INTRODUCTION}

In a mobile Internet era of fast paced, big data, information is the key and people want to get the most valuable information in a short period of time. In the face of the vast information, if information disseminators want to attract people's attention and to accurately convey information in a short time, information visualization becomes the best choice of the information transmission. Motion Graphics(MG) is a kind of communication design mode of doing creative design combined with text, graphics, sound, animation, video and other elements. In recent years with the rapid development in intelligent mobile client and network, $\mathrm{MG}$ is gaining widespread recognition and reception and opening up a new era of reading pictures. Different from the previous static graphic, MG is a dynamic graphic form of video. Dynamic graphic embodies the direction of an application in the field of modern visual communication and also reflects a kind of design concept or technique.

With the aid of motion graphic design, one type of popular information animation has quickly spread in the internet based on the restructuring of information and it features with a vivid and straightforward dynamic graphic variation, sound effect and an interesting commentary and completes the entire narrative of the theme by the similar form of animation. In the process of narrative, the information receiver can understand something, obtain knowledge, understand a truth, etc. The video is lively, interesting, and strongly impressive on people with transmissibility and popularization on the Internet.

\section{THE CONCEPT OF MOTION GRAPHICS}

Since the second half of the 20th century, the media of information has an unprecedented development with the generation of new media technology expanding the application range of graphic design and promoting the new change. The vision of graphic design in traditional printing is static, and in the new media, Graphic Design presents the multi-sensory dynamic performance. As a result, the use of dynamic media is made from the original Graphic Design into Motion Graphic Design. In film and television, dynamic graphic design has made great progress. Saul Bass is among the first to master the design of graphic design combined with film, creating the film starting with dynamic graphic design. Since the end of the 20th century, with the development of digital technology and network, the dynamic graphic design has become more mature. Both in China and other countries, a large number of Motion Graphics artists and studios have emerged, which create new forms of MG works, and also expand the scope of design and application of $\mathrm{MG}$, including digital advertising screens, website, intelligent mobile client, etc.

Although MG has been widely used in our life, either the research or the education of Motion Graphic Design in China is still at the beginning stage, the articles and works are comparatively scarce. The representative article is "Running in a dynamic world-graphic design turned to Motion Graphics" written by animation director and illustrator Gao $\mathrm{Lu}$ and published in the journal of Digital Art in 2008. This article gave the Chinese translation of the Motion Graphics, and pointed out that MG is a kind of comprehensive art in the field of digital design characterized by diversity with the application of different design categories and elements. MG fuses on-site shooting, visual effects, two-dimensional animation, threedimensional animation, graphic design, illustration design, font design, post-production, sound design and music production, interactive design, and so on. Broadly speaking, MG is a language with the fusion of the film and graphic design and time-based visual design.

In 2011, the first teaching material Motion Graphic Design was published in China which systematically introduces the Motion Graphic Design. The author summarizes the basic principles and rules from the space, time, motion and visual or auditory elements, and analyzes them by using some relevant examples. The book Motion Graphic Design was published in 2013, written by Xu Yibing and Xu Xiaoxiao giving a formula Motion Graphics = Graphic + Motion + Time, where Graphic, Motion and Time determine the research subject of motion graphics theory and also mean the three main lines of motion graphic design. This book illustrates some points on the differences between the animation design and motion graphic design. As a practitioner, in 2011, Beijing @ Real Eatate was 
the first MG animation. One of the creators Wei Tingting explained the MG from a different perspective at the website AT! She thought that many definitions about MG just explained the surface meaning of the word. The meaningful existence of MG lay in its function, which finished the function of explanation and illustration through the change or combination of the graphic symbol form signification. This is the core meaning of MG, namely the communication of information.

\section{THE CHARACTERISTICS OF THE INFORMATION TRANSMISSION DESIGN IN MOTION GRAPHICS}

From the perspective of information transmission, the characteristics of the motion graphic design are as follows.

- The information is presented based on the timeline. Motion graphic design is to convey information based on the timeline. The audience forms the information receiving order mainly through the order of the information elements on the timeline. The audience sees the images in a very short time. As a result, too complex graphics will not be accepted by audience who will not understand what you want to express. Therefore, in order to transmit information more intuitive and efficient, the design of the visual elements should avoid overly complex graphics or too much information in the same period of time. At the present, the most common style of graphic design is flat. This graphic style, through the combination of graphics, fonts and colors, is to achieve maximum information, reduce the interference of useless graphics and focus the audience quickly on the information.

- Separate information is transformed to some clear events. At the present, under the network media, information presents some characteristics, such as too much information, too vague and heterogeneous information. It is hard for people to find the useful information, understand the new information, learn everything fast or enhance work efficiency from a large amount of information. Motion graphic design needs to complete the entire narrative of the main theme and encyclopedic information based on the information mining, information analysis and information integration. The narrative is composed of a series of logical events and presents a complete, comprehensible and interesting mode of transmission based on the timeline "Fig. 1".

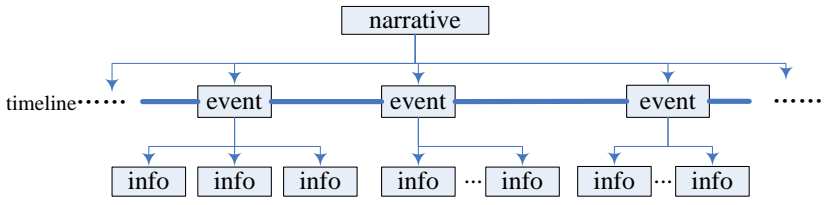

Fig. 1. Separate information is transformed to the narrative.

- Information Design is blended into graphic design. Information design is a way of using reasonable design to organize the data and information and to make the data and information transmission in a simple, fast, accurate form with strong visual punch. Motion graphic design commonly uses diagrams, charts, tables, graphs, maps, pictograms and so on.

- The MG animation is lively and interesting. In our current society, all designs need to put people first and start from the perspective of person's psychology. MG is a way of transmission which contains the multidimensional element such as seeing, hearing, perception and can activate audience's all-round sensory nerves. Motion graphical work does not necessarily need characters and scenes, but sometimes it can have roles and a short story, which can capture the audience's emotions. The work can better seize the audience, let the audience receive information in a relaxed and pleasant situation and achieve the purpose of persuading, informing, educating and entertaining the people as well as improving the timeliness and efficiency of information conveying.

\section{CASES Study OF Motion GRAPHICS}

Japan, the strange country was produced by Japanese designer Kenichi Tanaka in 2010. At that time, this MG animation was just his graduation work. The 11- minute MG animation made by using software of flash presented the story with black humor and dissected it into eight events to demonstrate Japan. These eight parts were the national character, Tokyo, food, technology, water, sushi, love, and suicide. The author used interesting graphics, charts and cooperated them with rich colors and appropriate dynamic changes, allowing the viewer to quickly understand the different side of the Japanese. The work was indeed thoughtprovoking "Fig. 2".

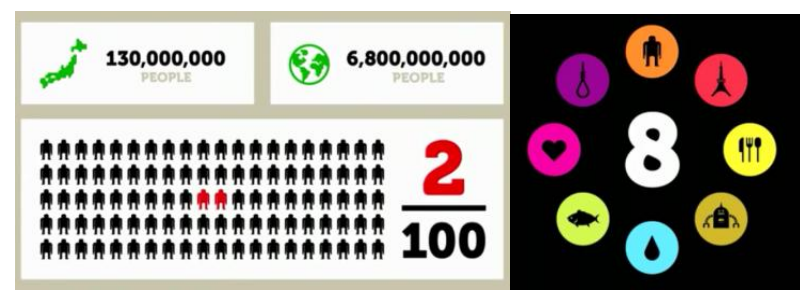

Fig. 2. MG animation Japan, the strange country

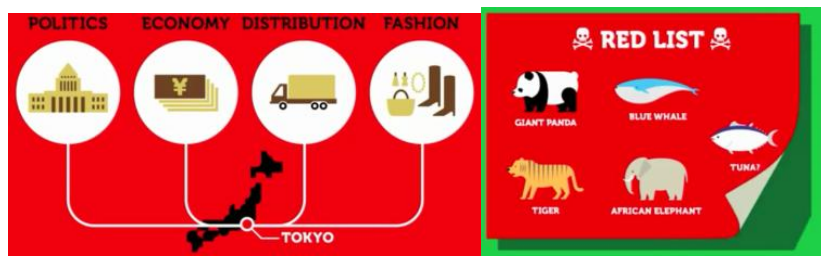

Fig. 3. MG animation Japan, the strange country

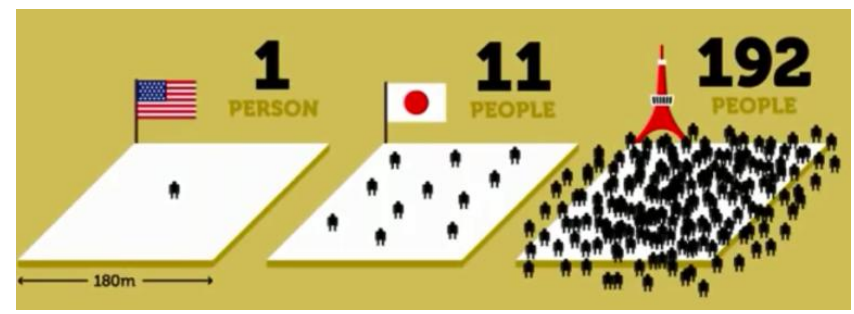

Fig. 4. MG animation Japan, the strange country 


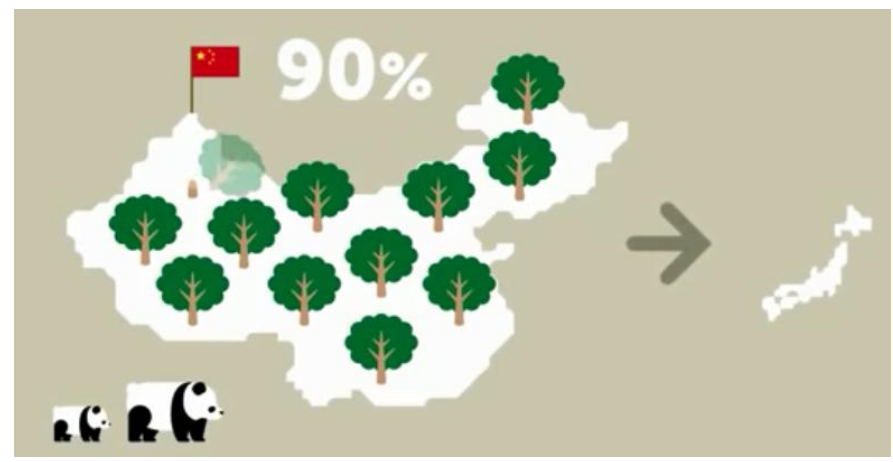

Fig. 5. MG animation Japan, the strange country

As mentioned above, the first MG animation Beijing @ Real Eatate in China, was concerned about the price of Beijing housing which has been the hotspot in recent years. The animation began from the house history and extended to the average living space of the Chinese people, the relationship between house price and families' income, the ecological environment of the house, etc. It analyzed in-depth the conditions of Beijing housing. Animation designer used infographics, graphic symbols, dynamic change, and vivid narrator commentary to convey professional knowledge reasonably and accurately. The valuable point of this animation was that the designer filtrated and combined information from a huge amount of information, and made the boring content visualized and interesting "Fig. 6", "Fig. 7", "Fig. 8", "Fig. 9", "Fig. 10".

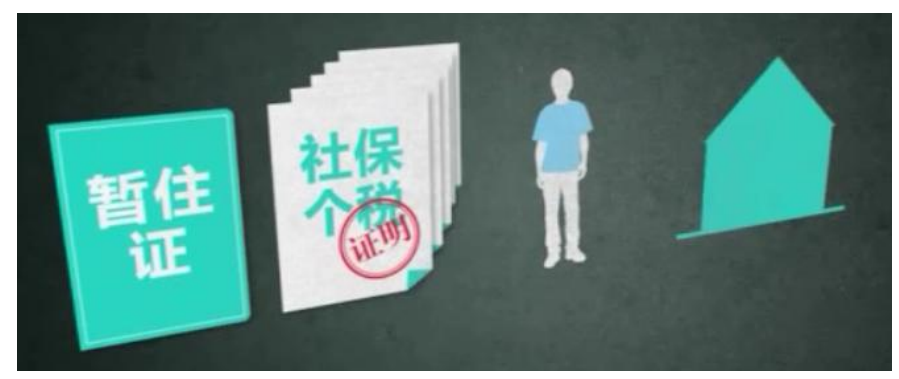

Fig. 6. MG animation Beijing @ Real Eatate

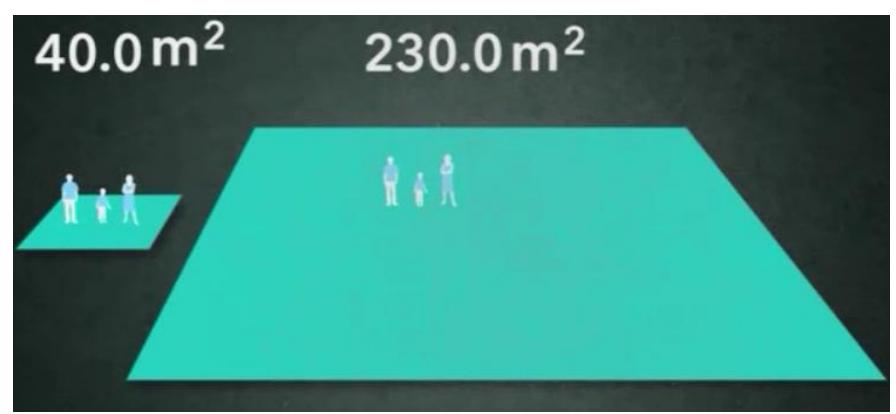

Fig. 7. MG animation Beijing @ Real Eatate

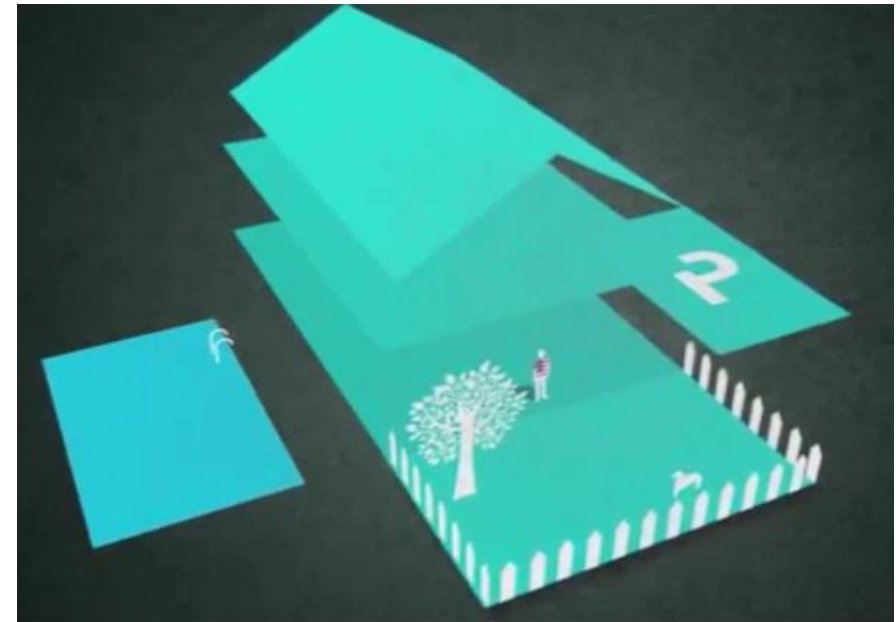

Fig. 8. MG animation Beijing @ Real Eatate

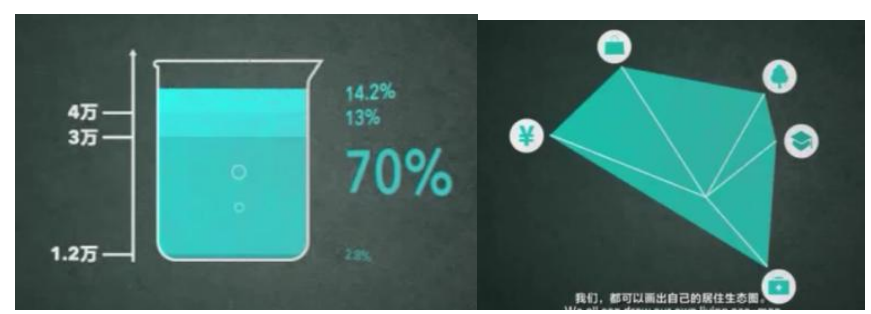

Fig. 9. MG animation Beijing @ Real Eatate

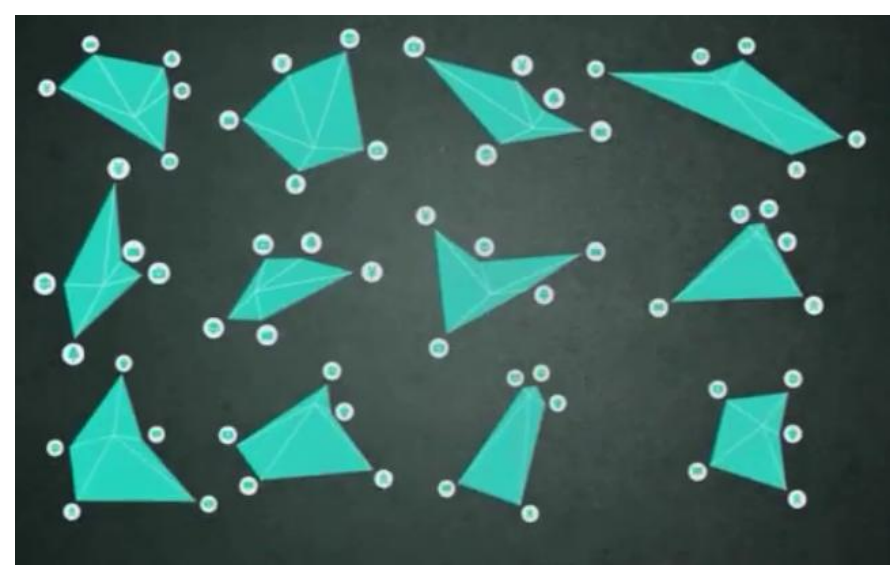

Fig. 10. MG animation Beijing @ Real Eatate

\section{CONCLUSION}

As an emerging expression of information design, MG has been gradually adopted in all fields of design. Dynamic information compiled by so much information is to make up the event, by using a chain of events to complete a narrative process. A good narrative and reasonable infographics can make MG animation more attractive.

\section{REFERENCES}

[1] Xu Yibing, Xu Xiaoxiao, "Motion Graphic Design", Southwest China Normal University Press, Sept.2011.

[2] Xu Yibing, Xu Xiaoxiao, "Motion Graphic Design”, Shanghai People's Fine Arts Publishing House, Mar.2013 